Supplementary

Annealed polycrystalline $\mathrm{TiO}_{2}$ interlayer of $\mathrm{n}-\mathrm{Si} / \mathrm{TiO}_{2} / \mathrm{Ni}$ photoanode for efficient photoelectrochemical water splitting

Chi-Huang Chuang, Yung-Yu Lai, Cheng-Hung Hou, and Yuh-Jen Cheng* Research Center for Applied Sciences, Academia Sinica, 128 Sec. 2, Academia Rd, Nankang, Taipei 115, Taiwan

*yjcheng@sinica.edu.tw

Table of contents

1. Sample fabrication.................................................

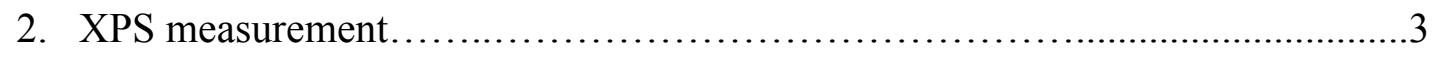

3. Supplementary figures............................................ 4

4. Supplementary note: Mott-Schottky analysis .......................... 9 


\section{Sample fabrication.}

n-Si (100) substrate with 1-10 ohm-cm resistivity and thickness of 430 um was used to fabricate photoanode. $\mathrm{p}+-\mathrm{Si}(100)$ substrate with $0.0015 \mathrm{ohm}-\mathrm{cm}$ resistivity and thickness of 430 um was used to fabricate reference $\mathrm{p}+-\mathrm{Si} / \mathrm{Ni}$ electrode. The $\mathrm{Si}$ substrate was first cleaned by ultrasonic bath $(10 \mathrm{~min})$ in acetone, ethanol, and di-ionized water. A Ti thin film was deposited on n-Si surface by e-gun deposition at $10^{-5}$ torr. The $\mathrm{n}-\mathrm{Si} / \mathrm{Ti}$ sample was transferred to a thermal annealing chamber. The thermal chamber temperature was ramped up at $5{ }^{\circ} \mathrm{C} / \mathrm{sec}$ till reaching target temperature and held at that temperature for a specific time. The chamber was purged by Ar at $0.5 \mathrm{slm}$ during thermal annealing. There was about $1 \%$ residual oxygen in chamber during annealing. The sample was then cooled down by the same Ar air flow until reaching room temperature. The sample was put back into the e-gun chamber to deposit a thin film of $\mathrm{Ni}$ to form $\mathrm{n}-\mathrm{Si} / \mathrm{TiO} 2 / \mathrm{Ni}$ photoanode structure. A Ti thin film of $1000 \AA$ was deposited on the backside of the sample to form ohmic contact. A copper wire was adhered to the Ti surface by silver past. The whole back surface was then covered by epoxy resin to fix the copper wire and isolate the back surface from electrolyte in water splitting experiment. 


\section{XPS Measurement.}

All XPS depth profiles were acquired by a PHI 5000 VersaProbe (ULVAC-PHI, Japan) system using a slice-and-view analysis scheme. During spectrum acquisition, a monochromatic $\mathrm{Al} \mathrm{K \alpha}$ X-ray beam with diameter of $100 \mu \mathrm{m}$ was applied on the investigated surface while it was neutralized by an $\mathrm{e}^{-}$and an $\mathrm{Ar}^{+}$beam, both with an acceleration voltage of $10 \mathrm{~V}$. A $1 \mathrm{kV} \mathrm{Ar}{ }^{+}$sputter beam with a beam current of $735 \mathrm{nA}$, rastering over a $2 \mathrm{~mm} \times 2 \mathrm{~mm}$ area, was used as the etching source. The sputtering time between each spectrum acquisition was set to be $0.2 \mathrm{~min}$ in order to achieve a good depth resolution. 


\section{Supplementary figures.}

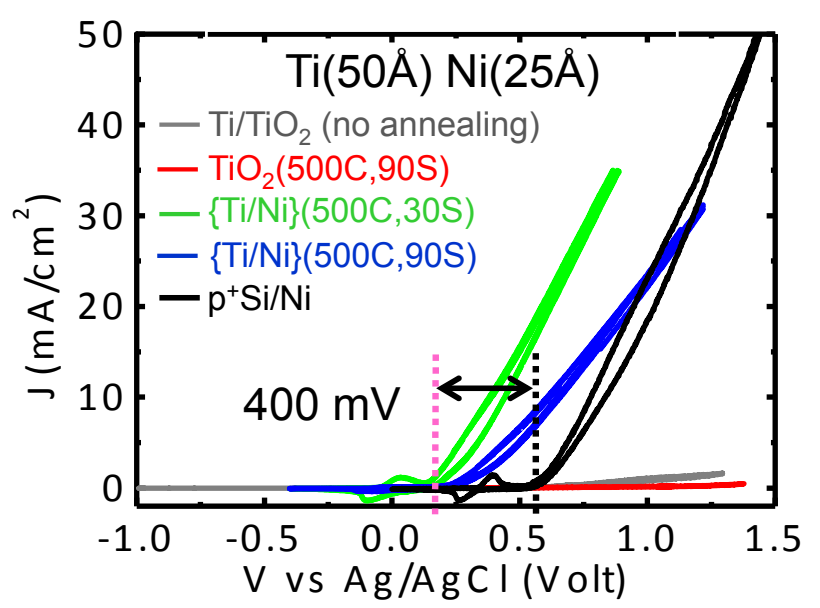

Figure S1. CV scans of various photoanode samples. n-Si coated with $\mathrm{Ti} / \mathrm{TiO} 2$ without thermal annealing or coated with $\mathrm{TiO} 2$ annealed at $500 \mathrm{C}$ for $90 \mathrm{sec}$, without $\mathrm{Ni}$ catalyst, does not show any photovoltage. n-Si coated with $\mathrm{Ti} / \mathrm{Ni}$ and annealed together at $500 \mathrm{C}$ for 30 and $90 \mathrm{sec}$ show lower photovoltage than the case when thermal annealing only applied to $\mathrm{TiO} 2$ interlayer before Ni deposition (Figure 1(c)).

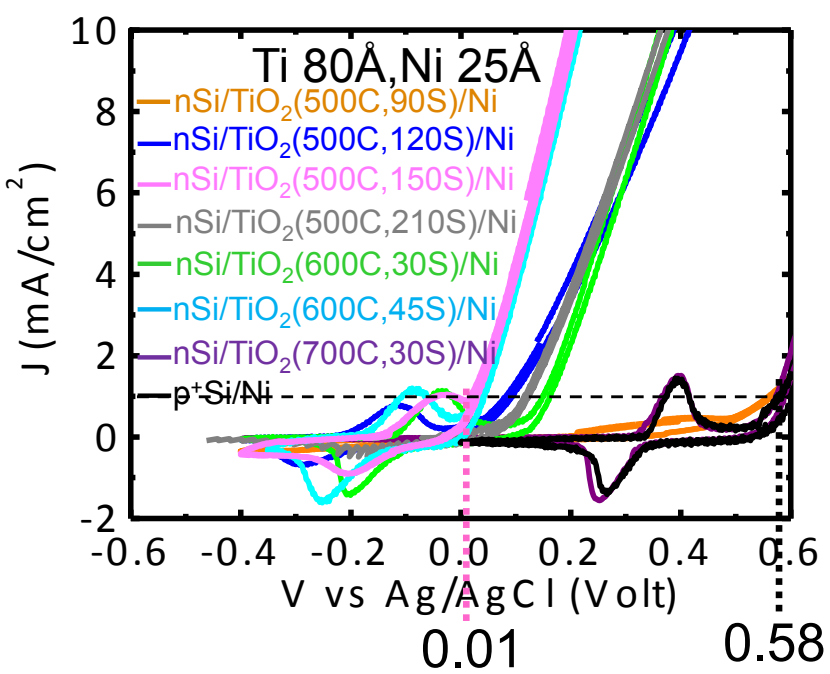

Figure S2. Magnification of Figure 2(b) to show the details of the turn on potentials of various samples with different $\mathrm{TiO}_{2}$ thermal annealing conditions. The turn on potential is defined at the potential when photocurrent is $1 \mathrm{~mA} / \mathrm{cm}^{2}$. 


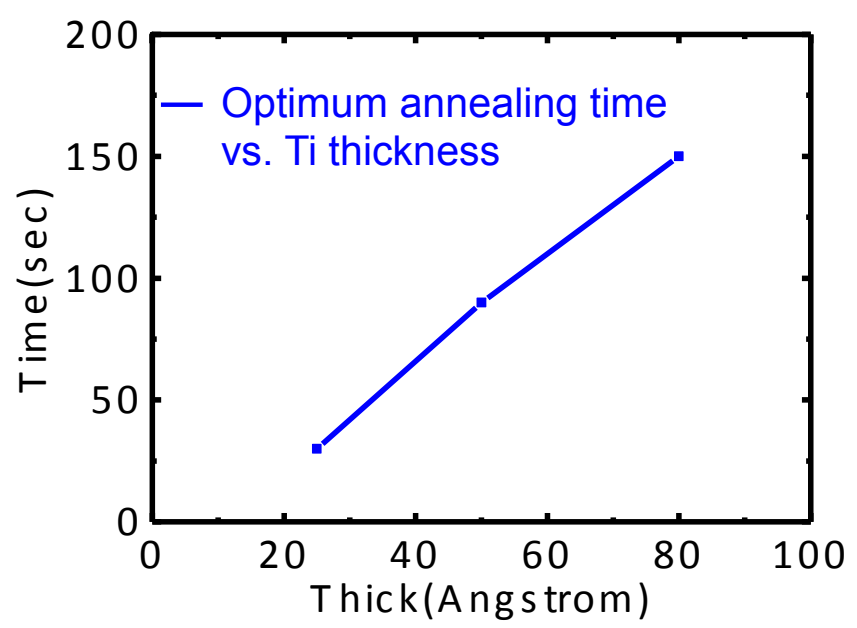

Figure S3. Optimum annealing time at $500 \mathrm{C}$ for $\mathrm{n}-\mathrm{Si} / \mathrm{TiO} 2 / \mathrm{Ni}$ sample shows linear dependence on the $\mathrm{TiO}_{2}$ thickness. 


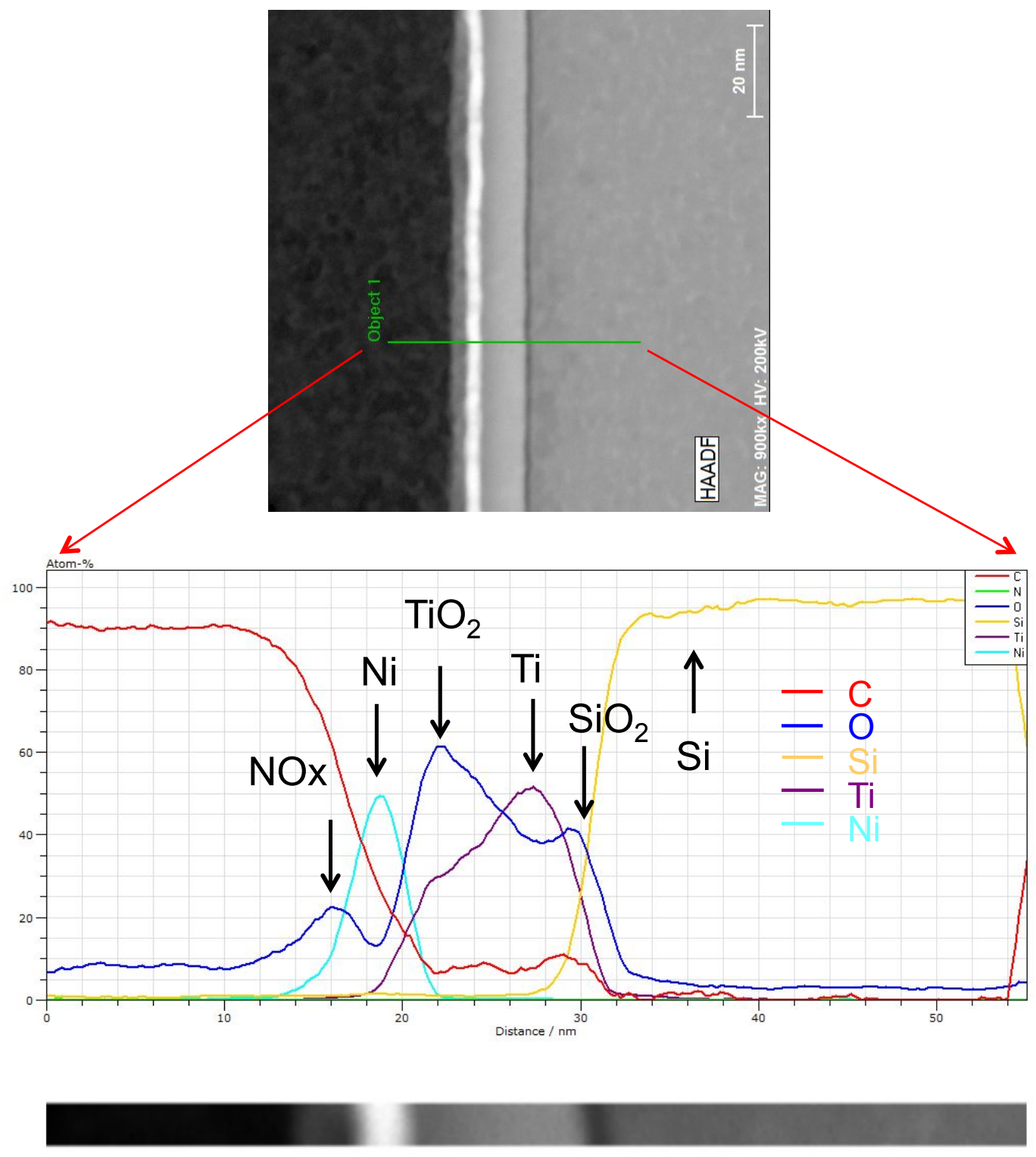

Figure S4. EDS composition analysis of $n-\mathrm{Si} / \mathrm{Ti}\left(\mathrm{TiO}_{\mathrm{x}}\right) / \mathrm{Ni}$ sample. There is no thermal annealing applied to the sample. 


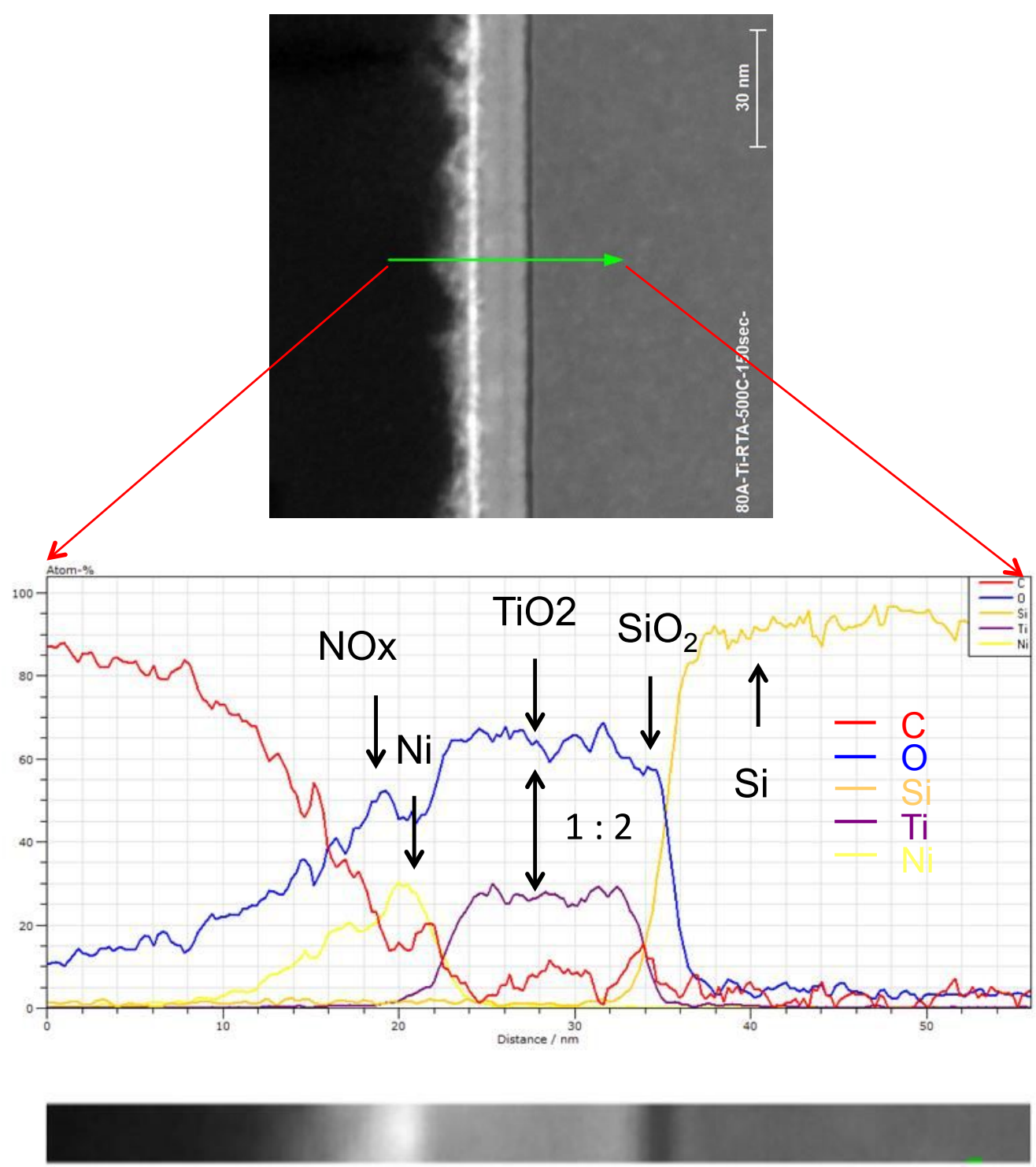

Figure S5. EDS composition analysis of $\mathrm{n}-\mathrm{Si} / \mathrm{TiO}_{2} / \mathrm{Ni}$ sample, where thermal annealing is applied to $\mathrm{TiO}_{2}$ interlayer at $500 \mathrm{C}$ for $150 \mathrm{sec}$. 


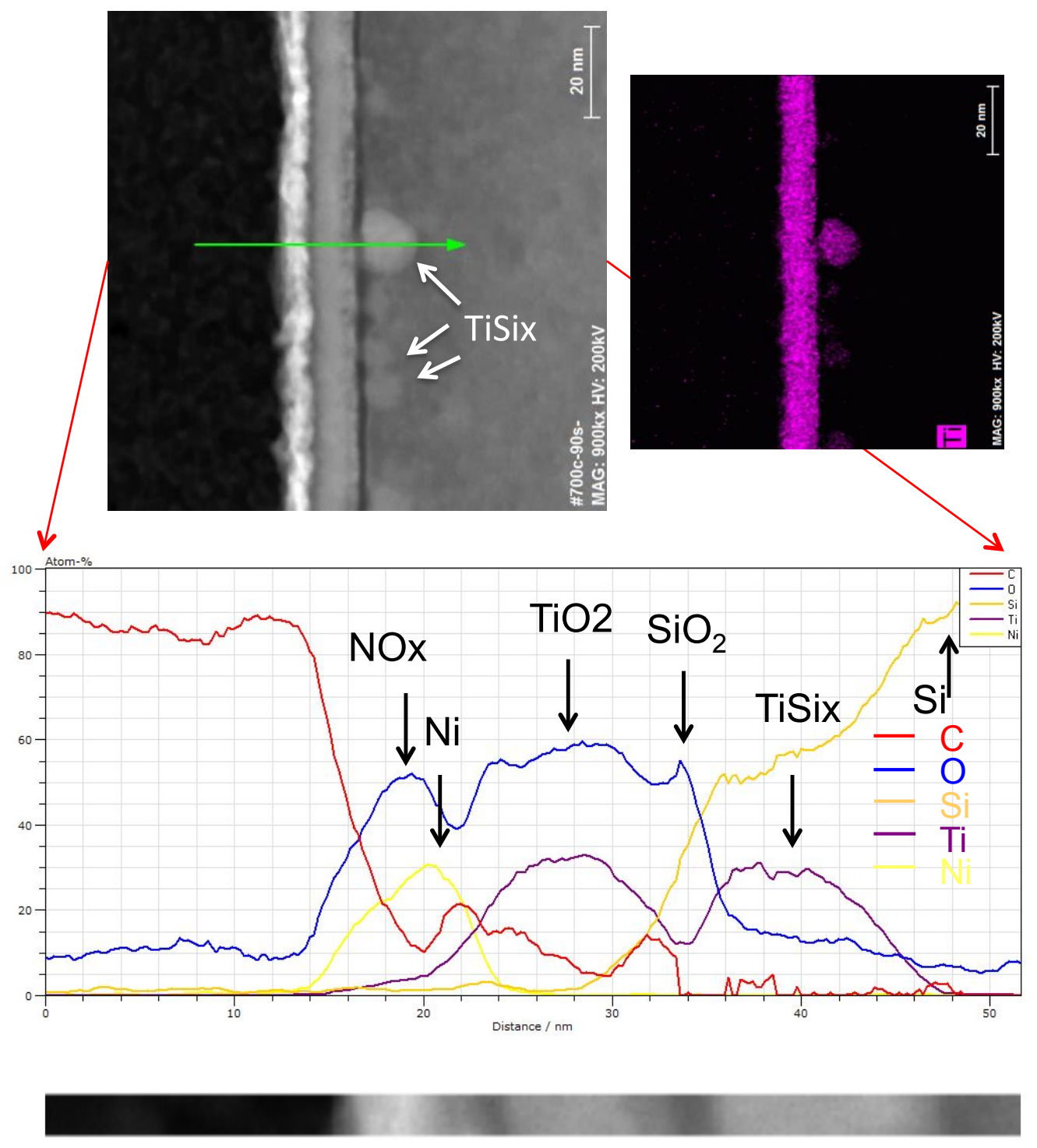

Figure S6. EDS composition analysis of $\mathrm{n}-\mathrm{Si} / \mathrm{TiO}_{2} / \mathrm{Ni}$ sample, where thermal annealing is applied to $\mathrm{TiO}_{2}$ interlayer at $700 \mathrm{C}$ for $30 \mathrm{sec}$. Ti is diffused into $\mathrm{Si}$ at some regions to form TiSix due to too high of annealing temperature. The false color map of Ti shows the diffusion of Ti into Si. 


\section{Supplementary note: Mott-Schottky analysis.}

The dependence of the inverse square capacitance $\mathrm{C}^{-2}$ of the space-charge region in a semiconductor on the bias potential is described by Mott-Schottky equation,

$$
\frac{1}{C^{2}}=\frac{2}{\varepsilon e N_{d}}\left(V-V_{f b}-\frac{k T}{e}\right),
$$

where $\square$ is the permittivity of $\mathrm{Si}, e$ is the electron charge, $N_{d}$ is the doping concentration of $\mathrm{Si}, \mathrm{V}$ is the bias potential, $\mathrm{V}_{\mathrm{fb}}$ is the flat band potential, $\mathrm{k}$ is the Boltzmann constant, $\mathrm{T}$ is the temperature. The barrier height $\mathrm{V}_{\mathrm{bh}}$ of the band bending is

$$
V_{b h}=V_{f b}+V_{n},
$$

where $\mathrm{V}_{\mathrm{n}}$ is the potential difference between the conduction band edge and the Fermi-level. $\mathrm{V}_{\mathrm{n}}$ is obtained from $\mathrm{V}_{\mathrm{n}}=\mathrm{kT} \ln \left(\mathrm{N}_{\mathrm{c}} / \mathrm{N}_{\mathrm{d}}\right)$, where $\mathrm{N}_{\mathrm{c}}=2\left(2 \square \mathrm{m}_{\mathrm{e}}{ }^{*} \mathrm{kT} / \mathrm{h}\right)^{3 / 2}$ and $\mathrm{m}_{\mathrm{e}}{ }^{*}$ is the effective electron mass. The slopes of the linear region of inverse square capacitance in the Mott-Schottky plot Figure 4(c) for n-Si/Ni and n-Si/ $/ 2 i O_{2} / \mathrm{Ni}$ annealed at $500 \mathrm{C}$ for 30 and $90 \mathrm{sec}$ are $7.68 \times 10^{14}, 6.70 \times 10^{14}$, and $5.91 \times 10^{14}, \mathrm{~F}^{-2}$ $\mathrm{cm}^{4} \mathrm{~V}^{-1}$. The corresponding doping density $N_{d}$ are $1.57 \times 10^{15}, 1.80 \times 10^{15}$, and $2.04 \times 10^{15}$. This gives resistivity in the range 2.9 to $2.3 \mathrm{ohm} \mathrm{cm}$, consistent with the range specified by supplier $1-10 \mathrm{ohm} \mathrm{cm}$. From the calcuclated $N_{d}$ values, $V_{n}$ is estimated to be $0.25 \mathrm{~V}$. The flat band potential $\mathrm{V}_{\mathrm{fb}}$ estimated from intercept between the extrapolated linear region and the $\mathrm{x}$-axis for three samples in Figure 4(c) are -0.66 , -0.73 , and $-0.80 \mathrm{~V}$ measured versus $\mathrm{Ag} / \mathrm{AgCl}$ reference electrode. The barrier height $\mathrm{V}_{\mathrm{bh}}$ for $\mathrm{n}-\mathrm{Si} / \mathrm{Ni}$ and $\mathrm{n}-\mathrm{Si} / \mathrm{TiO} 2 / \mathrm{Ni}$ annealed for 30 and $90 \mathrm{sec}$ are then $0.91,0.98$, and $1.05 \mathrm{~V}$. 